\title{
Localized salt-dependent aquagenic urticaria, a rare subtype of urticaria: a case report
}

Immunoallergy Department, Centro Hospitalar de Vila Nova de Gaia/Espinho, Vila Nova de Gaia, Portugal

\section{KEY WORDS}

aquagenic urticaria; localized;

hypertonic saline; sea water; salinity

\section{Corresponding author}

Luís Miguel dos Santos Vieira

Immunoallergy Department

Centro Hospitalar Vila Nova Gaia/Espinho

- EPE

Rua Conceição Fernandes 4434

502 Vila Nova de Gaia, Portugal

Phone: +351227865100

Fax: +35122786 5178

E-mail: miguel.santos.vieira@gmail.com

\section{Doi}

10.23822/EurAnnACI.1764-1489.56

\begin{abstract}
Summary
Aquagenic urticaria $(A U)$ is a rare form of chronic inducible urticaria elicited by water at any temperature. We describe the case of a 25-year-old atopic woman who presented to our unit with a 4-year history of recurrent urticarial rashes, highly pruritic, confined to the neck and lower part of the face, occurring solely on contact with sea water. The lesions were reproduced by challenge tests with aqueous $3.5 \% \mathrm{NaCl}$ and other hypertonic aqueous solutions but not with $20 \%$ glucose neither tap water.

Our case supports the existence of a distinct salt-dependent subtype of aquagenic urticaria (SDAU), which seems to be triggered mostly by sea bathing, affects young women and has a characteristic localization on the inferior facial contours and neck. To the best of our knowledge, only eight cases of SDAU have been reported in the literature.
\end{abstract}

\section{Introduction}

Aquagenic urticaria (AU) is a rare form of chronic inducible urticaria elicited by water at any temperature. Pruritic wheals develop immediately or within minutes at the sites of contact of the skin with water, irrespective of temperature or source, and clear within 30-60 min. Sweat, saliva, and even tears can precipitate a reaction. Symptoms often start in puberty, but cases presenting in childhood are also reported (1-3). It affects both genders, but has a female predominance. Most cases are sporadic but familial cases are also reported (4-10), and it was recently described in monozygotic twins (11), although no specific genetic mutation has been found yet.

Systemic symptoms are rare but have been reported, including wheezing, dysphagia, and respiratory distress $(12,13)$.
Water challenge test performed at body temperature for $20 \mathrm{~min}$ is recommended for diagnosis of AU. Differential diagnosis includes aquagenic pruritus, in which intense itching occurs after contact with water, but without visible skin lesions; cholinergic urticaria, where wheals develop in response to heat, exertion, sweating or emotional stress, and cold urticaria, characterized by rapid appearance of itching wheals and occasionally angioedema after cold stimulation $(14,15)$.

AU was first described by Shelley and Rawnsley, who reported three cases in 1964 (10) and fewer than 100 cases have since been published in the literature (13-19).

A distinct salt-dependent subtype of aquagenic urticaria (SDAU) seems to be triggered mostly by sea bathing, and affects young women, with a characteristic localization on the inferior facial 
contours and neck. To the best of our knowledge, only eight cases of SDAU have been reported in the literature (20-22).

\section{Case report}

A 25-year-old atopic woman, with a history of mild persistent allergic rhinitis for several years induced by both house dust mites and grass pollens, was referred to our department due to recurrent episodes of urticaria. She reported a 4-year history of recurrent urticarial rashes, highly pruritic, confined to the neck and lower part of the face, occurring solely on contact with sea water. The lesions appeared within about $10 \mathrm{~min}$ after the start of bathing in sea water and cleared spontaneously within 30 min after showering with tap water, leaving no residual mark. Her symptoms had occurred several successive summers while bathing in the Atlantic sea. The water temperature and the time of exposure were irrelevant. She did not report angioedema, wheezing or dyspnea during these episodes. Water ingestion and contact with swimming pool, river and tap water had no effect. No other types of inducible urticaria were present. There was no family history of atopy, and none of the girl's relatives reported similar skin reactions related to water exposure. Her symptoms were not associated with food ingestion or drug intake before water contact. She denied insect stings, minor trauma, infection, application of retinoids or any other irritant topical drug. Apart from oral contraceptives, she denied the use of other medications. Antihistamines taken before sea bathing were not effective.

A general physical examination was unrevealing, and there was a notable absence of dermographism. Laboratory evaluation, which included complete blood count, erythrocyte sedimentation rate, C-reactive protein, urine analysis, serum electrophoresis, immunoglobulins ( $G, A, M)$, thyroid function tests, anti-thyroid antibodies, antinuclear antibodies, rheumatoid factor and complement fractions (C3, C4, and C1q) revealed no abnormalities. Cryoglobulins were negative. There were no parasites or eggs in the stool sample. Level of total immunoglobulin E was $329 \mathrm{IU} / \mathrm{ml}$. Her skin tests were positive for house dust mites and grass pollens. An ice cube test elicited no reaction. Water challenge tests were performed with fresh sea water, tap water, aqueous hypertonic saline $(3.5 \% \mathrm{NaCL}$, iso-osmolar with sea water), and $20 \%$ glucose solutions and also with different hypertonic aqueous solutions (3.5\% KCL, 5.3\% NaHCO3) at $35^{\circ} \mathrm{C}$, by means of soaked compresses applied to the patient's submandibular area and neck and, as controls, to the antecubital flexures. The compresses were left in place for $20 \mathrm{~min}$. The patient reacted intensely with pruritus, micropapular eruption and erythema in the contact area (figure 1), to fresh sea water and to all solutions containing salts, but she did not react to a similar osmotic load with $20 \%$ glucose neither to tap water. Control tests in the antecubital flexures were all negative. We
Figure 1 - Localized erythema, micropapular eruption and scattered urticarial lesions 20 min after applying a compress soaked in fresh sea water and in different aqueous hypertonic solutions $(3.5 \%$ $\mathrm{NaCL}, 3.5 \% \mathrm{KCL}, 5.3 \% \mathrm{NaHCO} 3)$ at $35^{\circ} \mathrm{C}$ to the neck.

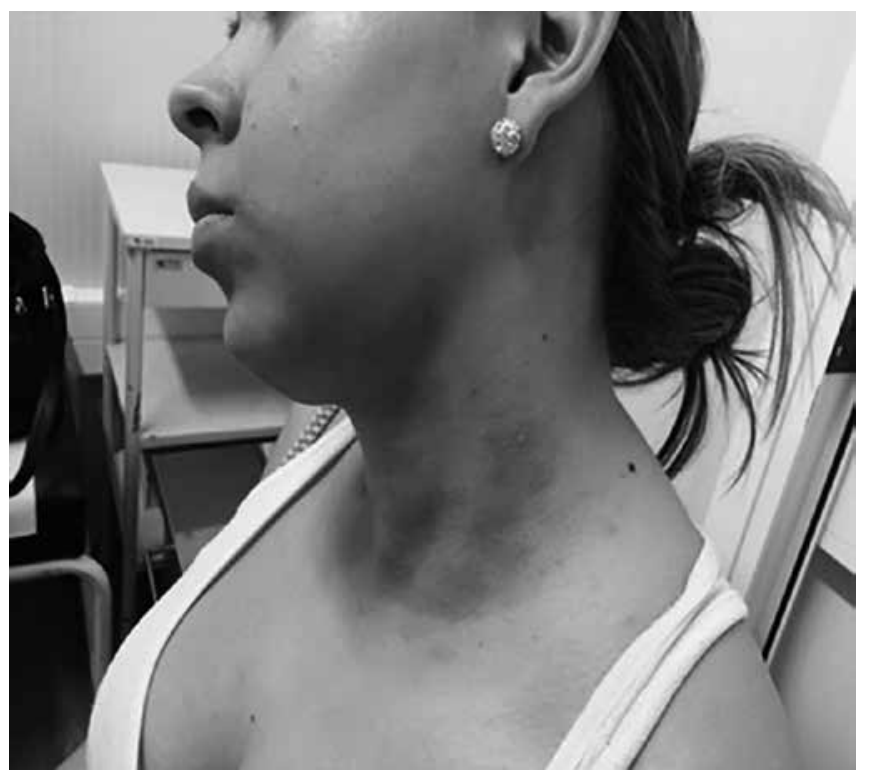

also performed a chemical analysis of a sea water sample (Praia de Salgueiros - Atlantic sea, Vila Nova de Gaia, Portugal), where she used to take baths, and we found a salinity of about $3.5 \%$. A diagnosis of SDAU was made. Short baths, immediate washing of the body surface with fresh water and application of protective hydrophobic barrier creams before sea bathing were recommended. We also prescribed medical treatment with oral levocetirizine $5 \mathrm{mg}$.

\section{Discussion}

Only a few cases of SDAU have been reported in the literature. The first one was described by Gallo et al. in 2001 (20): the patient was a young woman whose urticarial rashes were restricted to the lower facial contours, and were more intense on contact with sea water and hypertonic saline than with tap water. The same authors reported six further cases with similar characteristics in 2013 (21). The lesions appeared a few minutes after sea bathing, and had a selective localization on the inferior facial contours and neck, as in our patient. The challenge tests with hypertonic saline $(3.5 \% \mathrm{NaCl})$ were positive in all six patients. Two patients reacted also to tap water or to normal saline, but less intensely. One patient had also been tested with different water solutions that were iso-osmotic with sea water $(3.5 \% \mathrm{KCl}$, $5.3 \% \mathrm{NaHCO} 3$ and $20 \%$ glucose), and also with $3.5 \% \mathrm{NaCL}$, distilled and tap water. She only reacted to solutions containing 
salts $(3.5 \% \mathrm{NaCL}, 3.5 \% \mathrm{KCl}$, and $5.3 \% \mathrm{NaHCO} 3)$, as we stated in our patient.

The pathogenesis of $\mathrm{AU}$ is not well established, however, several hypotheses have been proposed (22). The authors who first described this condition proposed the formation of a toxic substance by the combination of water and sebum that causes mast cell degranulation (10). Further support for this hypothesis developed when Chalamidas and Charles (23) reported that patch testing with a patient's own sweat did not produce urticaria while patch testing with the patient's own sweat and sebum produced marked perifollicular urticaria. Czarnetzki et al. (8) hypothesized the existence of a water soluble antigen at the epidermal layer. The antigen diffuses into the dermis by water and then causes release of histamine from mast cells. Tkach (24) hypothesized that hypotonic water sources could lead to osmotic pressure changes, resulting in indirect provocation of urticaria. Others have stated that $5 \%$ saline was more effective than distilled water for eliciting the wheal-and-flare reaction. They hypothesized that the salt concentration and/or water osmolarity may influence the pathogenic process of AU, possibly by enhancing solubilization and penetration of a hypothetical epidermal antigen, in the same way as has been postulated for enhancement of organic solvents (25). Another proposed chemical mediator in $\mathrm{AU}$ is acetylcholine, because of the ability of the acetylcholine antagonist scopolamine to suppress wheal formation when applied to the skin before water contact (26). However, another study failed to reproduce this finding when pretreatment with atropine did not result in suppression of subsequent wheal formation (8).

Gallo et al (21) have recently suggested the involvement of a transient receptor potential vanilloid subtype (TRPV1) channel in the salt-dependent aquagenic urticaria's pathophysiology, based on previous findings of Ständer et al. (27), which reports the wide distribution of the TRPV1 in human skin including sensory nerve fibers, mast cells, epidermal keratinocytes, blood vessels, epithelial cells of hair follicle, eccrine sweat glands, and sebaceous glands. This receptor is a non-selective cation channel that could be activated by capsaicin (a substance not synthesized in the human body) or by the cannabinoid anandamide (2831 ), through an endogenous activation by an increase of temperature within a noxious range (above $42{ }^{\circ} \mathrm{C}$ ), and by protons ( $\mathrm{pH}$ below 5.9). This non selective sodium permeable channel can act as a "cellular sensor" of osmotic concentration and its presence on mast cells could lead to activation and therefore to the histamine release.

Because of its unclear pathogenesis, treatment options are limited and produced varied responses at best. Antihistamines are usually used as first line treatment, up to four times the standard single daily dose to treat aquagenic urticaria, although response varies from patient to patient.
In refractory cases ultraviolet monotherapy alone or in combination with antihistamines have been used with some efficacy (32). It has been hypothesized that the ultraviolet therapy induces thickening of the epidermis, which may prevent water penetration and further interaction in the epidermal milieu. Other therapeutic options have included topical barrier creams and acetylcholine antagonists (26) and it was recently described a case of aquagenic urticaria successfully treated with omalizum$\mathrm{ab}(33)$.

Treatment of SDAU consists of reducing the time contact with sea water and the application of barrier creams before sea bathing. Oral antihistamines are also required, but response may vary.

\section{Conclusions}

We described a rare case of a young women with aquagenic urticaria triggered only by sea bathing and strictly localized on the inferior facial contours and neck.

Urticarial lesions were reproduced by challenges with aqueous $3.5 \% \mathrm{NaCl}$ and other hypertonic aqueous solutions $(3.5 \%$ KCL, $5.3 \% \mathrm{NaHCO} 3$ ) but not with $20 \%$ glucose neither tap water.

Our case, as previous reports, suggests the existence of a SDAU and supports the hypothesis that the salt concentration and/or osmolarity of water may influence the pathogenic process of aquagenic urticaria. We think the reaction to be dependent on the salinity of the water rather than on its osmolality, because the patient did not react to hypertonic glucose.

\section{Patient consent}

Written informed consent was obtained from the patient for publication of this case report and any accompanying images.

\section{Conflict of interest}

The authors declare that they have no conflicts of interest.

\section{References}

1. Dice JP. Physical urticaria. Immunol Allergy Clin North Am 2004; 24(2):225-46.

2. Park H, Kim HS, Yoo DS, Kim JW, Kim CW, Kim SS, et al. Aquagenic urticaria: a report of two cases. Ann Dermatol 2011; 23Sup$\mathrm{pl3:S371-4.}$

3. Frances AM, Fiorenza G, Frances RJ. Aquagenic urticaria: report of a case. Allergy Asthma Proc 2004; 25(3):195-7.

4. Pitarch G, Torrijos A, Martínez-Menchón T, Sánchez-Carazo JL, Fortea JM. Familial aquagenic urticaria and Bernard-Soulier syndrome. Dermatology 2006; 212(1):96-7.

5. Treudler R, Tebbe B, Steinhoff M, Orfanos CE. Familial aquagenic urticaria associated with familial lactose intolerance. J Am Acad Dermatol 2002; 47(4):611-3.

6. Seize MB, Ianhez M, de Souza PK, Rotta O, Cestari Sda C. Famil- 
ial aquagenic urticaria: report of two cases and literature review. An Bras Dermatol 2009; 84(5):530-3.

7. Bonnetblanc JM, Andrieu-Pfahl F, Meraud JP, Roux J. Familial aquagenic urticaria. Dermatologica 1979; 158(6):468-70.

8. Czarnetzki BM, Breetholt KH, Traupe H. Evidence that water acts as a carrier for an epidermal antigen in aquagenic urticaria. J Am Acad Dermatol 1986; 15(4Pt1):623-7.

9. Tromovitch TA. Urticaria from contact with water. Calif Med $1967 ; 106(5): 400-1$

10. Shelley WB, Rawnsley HM. Aquagenic urticaria. Contact sensitivity reaction to water. JAMA 1964; 189:895-8.

11. Kai AC, Flohr C. Aquagenic urticaria in twins. World Allergy Organ J 2013; 6(1):2.

12. Baptist AP, Baldwin JL. Aquagenic urticaria with extracutaneous manifestations. Allergy Asthma Proc 2005; 26(3):217-20.

13. Luong KV, Nguyen LT. Aquagenic urticaria: report of a case and review of the literature. Ann Allergy Asthma Immunol 1998; 80(6):483-5.

14. Magerl M, Borzova E, Giménez-Arnau A, Grattan CE, Lawlor F, Mathelier-Fusade $\mathrm{P}$, et al. The definition and diagnostic testing of physical and cholinergic urticarias EAACI/GA2LEN/EDF/UNEV consensus panel recommendations. Allergy 2009; 64(12):1715-21.

15. Zuberbier T, Asero R, Bindslev-Jensen C, Walter Canonica G, Church MK, Giménez-Arnau A, et al. EAACI/GA2/EDF/WAO guideline: definition, classification and diagnosis of urticaria. Allergy 2009; 64(10):1417-26.

16. Yavuz ST, Sahiner UM, Tuncer A, Sackesen C. Aquagenic urticaria in 2 adolescents. J Investig Allergol Clin Immunol 2010; 20(7):624-5.

17. Frances AM, Fiorenza G, Frances RJ. Aquagenic urticarial: report of a case. Allergy and Asthma Proc 2004; 25(3):195-7.

18. Gimenez-Arnau A, Serra-Baldrich E, Camarasa JG. Chronic aquagenic urticaria. Acta Derm Venereol 1992; 72(5):389.

19. Bayle P, Gadroy A, Messer L, Bazex J. Localized Aquagenic urticaria: efficacy of a barrier cream. Contact Dermatitis 2003; 49(3):160-1.
20. Gallo R, Cacciapuoti M, Cozzani E, Guarrera M. Localized aquagenic urticaria dependent on saline concentration. Contact Dermatitis 2001; 44(2):110-1.

21. Gallo R, Goncalo M, Cinotti E, Cecchi F, Parodi A. Localized salt-dependent aquagenic urticaria: a subtype of aquagenic urticaria? Clin Exp Dermatol 2013; 38(7):754-7.

22. Margerin F, Wettlé C, Merklen-Djafri C, Cribier B. Urticaire aquagénique localisée à l'eau de mer. Ann Dermatol Venereol 2015; 142(12):771-5.

23. Chalamidas SL, Charles CR. Aquagenic urticaria. Arch Dermatol 1971; 104(5):541-6.

24. Tkach JR. Aquagenic urticaria. Cutis 1981; 28(4):454,463.

25 . Hide M, Yamamura Y, Sanada S, Yamamoto S. Aquagenic urticaria: a case report. Acta Derm Venereol 2000; 80(2):148-9.

26. Sibbald RG, Black AK, Eady RA, James M, Greaves MW. Aquagenic urticaria: evidence of cholinergic and histaminergic basis. $\mathrm{Br}$ J Dermatol 1981; 105(3):297-302.

27. Ständer S, Moormann C, Schumacher M, Buddenkotte J, Artuc M, Shpacovitch V, et al. Expression of vanilloid receptor subtype 1 in cutaneous sensory nerve fibers, mast cells, and epithelial cells of appendage structures. Exp Dermatol 2004; 13(3):129-39.

28. Zygmunt PM, Petersson J, Andersson DA, Chuang H, Sørgård M, Di Marzo V, et al. Vanilloid receptors on sensory nerves mediate the vasodilator action of anandamide. Nature 1999; 400(6743):452-7.

29. Smart D, Gunthorpe MJ, Jerman JC, Nasir S, Gray J, Muir AI, et al. The endogenous lipid anandamide is a full agonist at the human vanilloid receptor (hVR1). Br J Pharmacol 2000; 129(2):227-30.

30. Szolcsányi J. Are cannabinoids endogenous ligands for the VR1 capsaicin receptor? Trends Pharmacol Sci 2000; 21(2):41-2.

31. Di Marzo V, Bisogno T, De Petrocellis L. Anandamide: some like it hot. Trends Pharmacol Sci 2001; 22(7):346-9.

32. Martinez-Escribano JA, Quecedo E, De la Cuadra J, Frias J, Sanchez-Pedreno P, Aliaga A. Treatment of aquagenic urticaria with PUVA andastemizole. J Am Acad Dermatol 1997; 36(1):118-9.

33. Rorie A, Gierer S. A case of Aquagenic urticaria successfully treated with omalizumab. J Allergy Clin Immunol Pract 2016; 4(3):547-8. 